\title{
Efficacy of frovatriptan and other triptans in the treatment of acute migraine of hypertensive and normotensive subjects: a review of randomized studies
}

\author{
V. Tullo $\cdot$ G. Bussone $\cdot$ S. Omboni $\cdot$ P. Barbanti $\cdot$ P. Cortelli $\cdot$ M. Curone $\cdot$ \\ C. Peccarisi $\cdot$ C. Benedetto $\cdot$ D. Pezzola $\cdot$ D. Zava $\cdot$ G. Allais
}

(C) Springer-Verlag Italia 2013

\begin{abstract}
Migraine might be associated with high blood pressure (BP), which can cause more severe and more difficult to treat forms of headache. To evaluate the efficacy of frovatriptan and other triptans in the acute treatment of migraine, in patients classified according to a history of arterial hypertension, enrolled in three randomized, double-blind, crossover, Italian studies. Migraineurs with or without aura were randomized to frovatriptan $2.5 \mathrm{mg}$ or rizatriptan $10 \mathrm{mg}$ (study 1), frovatriptan $2.5 \mathrm{mg}$ or zolmitriptan $2.5 \mathrm{mg}$ (study 2), frovatriptan $2.5 \mathrm{mg}$ or almotriptan $12.5 \mathrm{mg}$ (study 3). After treating up to three episodes of migraine in 3 months with the first treatment, patients switched to the alternate treatment for the next 3 months. The present analysis assessed triptan efficacy in 60 subjects with a history of treated or untreated essential
\end{abstract}

V. Tullo · G. Bussone $\cdot$ M. Curone $\cdot$ C. Peccarisi

Department of Clinical Neuroscience, Headache Unit,

C. Besta Neurological Institute and Foundation, Milan, Italy

S. Omboni ( $\square)$

Italian Institute of Telemedicine, Via Colombera,

29, 21048 Solbiate Arno (Varese), Italy

e-mail: stefano.omboni@iitelemed.org

P. Barbanti

Unit for Treatment and Research of Headaches and Pain,

IRCCS San Raffaele Pisana, Rome, Italy

P. Cortelli

Neurological Clinic, Department of Neurological Science,

University of Bologna, Bologna, Italy

C. Benedetto - G. Allais

Department of Gynecology and Obstetrics, Women's Headache

Center, University of Turin, Turin, Italy

D. Pezzola $\cdot$ D. Zava

Medical Department, Istituto Lusofarmaco d'Italia, Milan, Italy arterial hypertension (HT) and in 286 normotensive (NT) subjects. During the study, migraine attacks with aura were significantly more prevalent in HT subjects (21 vs. $13 \%$ NT, $p<0.001)$. The proportion of pain free at $2 \mathrm{~h}$ did not significantly differ between HTs and NTs for either frovatriptan (25 vs. $26 \%$ ) or the comparators (33 vs. $32 \%)$. Pain relief was achieved in significantly $(p<0.05)$ fewer episodes in HT subjects for both frovatriptan (41 vs. $52 \%$ NT) and the comparators (48 vs. $58 \%$ ). Relapses at $48 \mathrm{~h}$ were similarly low in HTs and NTs with frovatriptan ( 29 vs. $31 \%)$, while they were significantly $(p<0.05)$ larger in HTs (62\%) than in NTs (44\%) with comparators. No BP or heart rate increment was observed during the study in HT subjects. No difference in tolerability was reported between HTs and NTs. In conclusion, HT individuals tend to be less responsive than NT migraineurs to triptan therapy. However, frovatriptan, in contrast to other triptans, seems to have a sustained antimigraine effect in both HT and NT patients.

Keywords Migraine - Frovatriptan - Rizatriptan . Zolmitriptan $\cdot$ Almotriptan $\cdot$ Arterial hypertension

\section{Introduction}

Several studies have reported that hypertension may not infrequently be associated with migraine and may even induce migraine chronification $[1,2]$. According to the current knowledge, arterial hypertension is believed to enhance the effects of migraine on the vascular wall and concur to the further impairment of the endothelial function in the cerebral vasculature, leading to exacerbation of the frequency and severity of attacks [1, 3, 4]. In addition, individuals with migraine and hypertension have a higher 
risk of developing cardiovascular disease, such as ischemic stroke, than normotensive individuals $[2,5]$.

Triptans are currently recommended for treating more severe forms of migraine, thus also potentially including episodes occurring in subjects suffering from arterial hypertension [6, 7]. However, presently there is no specific large scale trial which assessed the efficacy of triptans for treating acute migraine attacks in hypertensive individuals.

To bridge this void we settled a retrospective analysis of three previously published randomized, double-blind, cross-over, Italian studies [8-10]. In this analysis we compared the efficacy of frovatriptan, an antimigraine agent of the triptan class characterized by a long duration of action and thus a protracted analgesic activity [11], with that of other triptans, in patients classified according to a history of high blood pressure.

\section{Methods}

Study population and design

The three studies shared a similar design, whose details are extensively reported in the original publications [8-10]. In brief, the studies included subjects of both genders, aged 18-65 years, with a current history of migraine with or without aura, according to International Headache Society criteria [12], and with at least one, but no more than six migraine attacks per month for 6 months prior to entering the study. In the present retrospective analysis, we separately selected hypertensive and normotensive subjects. An entry office systolic blood pressure $\geq 140 \mathrm{mmHg}$ or an office diastolic blood pressure $\geq 90 \mathrm{mmHg}$ or a history of antihypertensive drug treatment indicated a positive history for hypertension. Normotension was defined by an office systolic blood pressure $<140 \mathrm{mmHg}$ and an office diastolic blood pressure $<90 \mathrm{mmHg}$ in the absence of any specific antihypertensive drug treatment or previous diagnosis of hypertension.

The studies had a multicenter, randomized, double blind, cross-over design, and involved 33 different centers across Italy. Each patient received frovatriptan $2.5 \mathrm{mg}$ or rizatriptan $10 \mathrm{mg}$ (first study) [8], frovatriptan $2.5 \mathrm{mg}$ or zolmitriptan $2.5 \mathrm{mg}$ (second study) [9], and frovatriptan $2.5 \mathrm{mg}$ or almotriptan $12.5 \mathrm{mg}$ (third study) [10], in a randomized sequence. After treating 1-3 episodes of migraine in no more than 3 months with the first treatment, the patient had to switch to the other treatment and treated a maximum of three episodes of migraine in no more than 3 months with the second treatment. Subjects having no migraine episodes during one of the two observation periods were excluded from the study. Each subject was asked to visit the center three times during the study. Blood pressure was measured at each visit by a standard mercury sphygmomanometer according to current recommendations [13]. The arm cuff was wrapped preferentially around the non-dominant arm and kept at heart level during every blood pressure measurement. Three measurements, taken at $5 \mathrm{~min}$ intervals after $5 \mathrm{~min}$ of rest in the sitting position, were averaged and used as the office blood pressure reference value. Systolic and diastolic blood pressure values were taken at the time of the first and fifth Korotkoff sound, respectively. Heart rate was measured by the palpatory method at the radial artery level after each blood pressure measurement.

\section{Data analysis}

As in the original publications, this pooled analysis was based on the intention-to-treat population, defined as all patients treating at least one attack in each treatment period.

The study endpoints were quantified according to IHS Guidelines as follows [12]: (a) pain-free episodes at $2 \mathrm{~h}$ (absence of migraine $2 \mathrm{~h}$ after the intake of one dose of study drug), (b) pain relief at $2 \mathrm{~h}$ (decrease in migraine intensity from severe or moderate to mild or none $2 \mathrm{~h}$ after the intake of one dose of study drug), (c) relapse within $48 \mathrm{~h}$ (episode pain free at $2 \mathrm{~h}$ and headache of any severity returning within $48 \mathrm{~h}$, or requiring the use of rescue medication or of a second dose of study drug).

A safety analysis was carried out on the intention-totreat population, by calculating the incidence of adverse events and changes in vital signs during the study and comparing them between hypertensive and normotensive subjects, regardless of the type of treatment.

Continuous variables were summarized by computing average values and standard deviations (SD), while categorical variables by computing the absolute value and the frequency (as percentage). Study endpoints were compared between hypertensive and normotensive groups by a $t$ test of Student's (continuous variables) or by a $\chi^{2}$ test (categorical variables). The level of statistical significance was kept at 0.05 throughout the whole study.

\section{Results}

The intention-to-treat population of the three studies pooled together consisted of 346 subjects, of which 60 were classified as having hypertension and 286 as normotensive. Baseline demographic and clinical characteristics of the intention-to-treat population for the two groups of subjects are reported in Table 1. Hypertensive subjects were older and with a higher body mass index than normotensive ones, with a significantly larger prevalence of 
Table 1 Demographic and baseline clinical characteristics of the 60 hypertensive subjects and of the 286 normotensive subjects of the intention-to-treat population

\begin{tabular}{|c|c|c|c|}
\hline & $\begin{array}{l}\text { Hypertensive } \\
\text { subjects } \\
(n=60)\end{array}$ & $\begin{array}{l}\text { Normotensive } \\
\text { subjects } \\
(n=286)\end{array}$ & $p$ value \\
\hline $\begin{array}{l}\text { Age }(\text { years, } \\
\text { mean } \pm \text { SD) }\end{array}$ & $45 \pm 9$ & $37 \pm 10$ & $<0.01$ \\
\hline Males $(n, \%)$ & $16(27)$ & $43(15)$ & $<0.05$ \\
\hline $\begin{array}{l}\mathrm{BMI}\left(\mathrm{kg} / \mathrm{m}^{2}\right. \\
\text { mean } \pm \mathrm{SD})\end{array}$ & $24 \pm 5$ & $23 \pm 3$ & $<0.05$ \\
\hline $\begin{array}{l}\text { Age at onset of } \\
\text { migraine (years, } \\
\text { mean } \pm \text { SD) }\end{array}$ & $20 \pm 12$ & $18 \pm 8$ & NS \\
\hline $\begin{array}{l}\text { Migraine attack } \\
\text { duration }<2 \text { days } \\
(n, \%)\end{array}$ & $19(32)$ & $60(21)$ & NS \\
\hline $\begin{array}{l}\text { MIDAS score } \\
\quad(\text { mean } \pm \mathrm{SD})\end{array}$ & $19 \pm 13$ & $22 \pm 16$ & NS \\
\hline $\begin{array}{l}\text { Use of triptans in the } \\
\text { previous } 3 \text { months } \\
(n, \%)\end{array}$ & $37(62)$ & $166(58)$ & NS \\
\hline $\begin{array}{l}\text { Migraine attacks with } \\
\text { aura }(n, \%)\end{array}$ & $3(5)$ & $29(10)$ & NS \\
\hline $\begin{array}{l}\text { Concomitant diseases } \\
(n, \%)\end{array}$ & $36(60)$ & $89(31)$ & $<0.01$ \\
\hline $\begin{array}{l}\text { Abnormal } \\
\text { cardiovascular } \\
\text { examination }(n, \%)\end{array}$ & $5(8)$ & $1(1)$ & $<0.01$ \\
\hline $\begin{array}{l}\text { Cardiovascular drugs } \\
(n, \%)\end{array}$ & $2(3)$ & $1(1)$ & $<0.05$ \\
\hline $\begin{array}{l}\text { Antihypertensive } \\
\text { treatment }(n, \%)\end{array}$ & $15(25)$ & - & - \\
\hline Beta-blockers & $8(53)$ & - & - \\
\hline$A R B s$ & $6(10)$ & - & - \\
\hline ACE-inhibitors & $1(2)$ & - & - \\
\hline $\begin{array}{l}\mathrm{SBP}(\mathrm{mmHg} \\
\text { mean } \pm \mathrm{SD})\end{array}$ & $134 \pm 12$ & $115 \pm 10$ & $<0.01$ \\
\hline $\begin{array}{l}\mathrm{DBP}(\mathrm{mmHg} \\
\text { mean } \pm \mathrm{SD})\end{array}$ & $87 \pm 8$ & $73 \pm 8$ & $<0.01$ \\
\hline $\mathrm{HR}(\mathrm{bpm}$, mean $\pm \mathrm{SD})$ & $75 \pm 10$ & $72 \pm 8$ & $<0.05$ \\
\hline
\end{tabular}

Data are shown as mean $( \pm \mathrm{SD})$, or absolute $(n)$ and relative frequency $(\%), p$ value refers to the statistical significance of the between-group difference

$B M I$ Body Mass Index, MIDAS MIgraine Disability Assessment, ARB Angiotensin-Receptor Blockers, $A C E$ Angiotensin Converting Enzyme, SBP Systolic Blood Pressure, DBP Diastolic Blood Pressure, $H R$ Heart Rate

males, concomitant diseases, cardiovascular abnormalities and use of cardiovascular drugs. As expected, entry office blood pressure values were significantly higher in the hypertensive patients. This was the case also for office heart rate values.

During the treatment period, in both the normotensive and hypertensive population, moderate or severe attacks were significantly more common than mild attacks, but no between group difference was observed (moderate-severe attacks: $79 \%$ hypertensives vs. $81 \%$ normotensives, mild attacks: 21 vs. $19 \%$ ). Average intensity of all attacks prior to triptan intake was similar between hypertensive $(2.0 \pm 0.7)$ and normotensive subjects $(2.1 \pm 0.7, p=\mathrm{NS})$. In contrast, during the treatment period, migraine attacks with aura were significantly $(p<0.01)$ more prevalent in hypertensive $(21 \%)$ than in normotensive subjects $(13 \%)$.

As summarized in Fig. 1, at $2 \mathrm{~h}$ the rates of pain free episodes did not significantly differ between hypertensive and normotensive subjects either for attacks treated with frovatriptan or for those treated with the comparators. Pain relief was achieved at $2 \mathrm{~h}$ in significantly fewer episodes in hypertensive subjects for either frovatriptan or comparators. The rate of relapse at $48 \mathrm{~h}$ with frovatriptan was similarly low in hypertensive and normotensive subjects, while with the comparators it was significantly larger in hypertensives.

At the end of the study, no increment in blood pressure was observed in either normotensive (baseline minus end of treatment: $+0.6 \pm 9.6 \mathrm{mmHg}$ systolic and $+0.6 \pm 7.6$ $\mathrm{mmHg}$ diastolic, $p=\mathrm{NS}$ for both) or hypertensive subjects $(-6.4 \pm 1.6 \mathrm{mmHg}$ systolic and $-3.9 \pm 8.5 \mathrm{mmHg}$ diastolic, $p<0.01$ vs. baseline). Heart rate was not influenced by treatment (hypertensives: $+0.4 \pm 8.2 \mathrm{bpm}$; normotensives: $-0.1 \pm 7.7 \mathrm{bpm}$; $(p=\mathrm{NS})$.

During treatment, drug-related adverse events were reported by $12 \%$ of hypertensive subjects and by $10 \%$ of normotensive subjects, with a non-statistically significant difference between the two study groups. Side-effects attributed to study treatment accounted for $43 \%$ of total events in the hypertensive and $51 \%$ in the normotensive
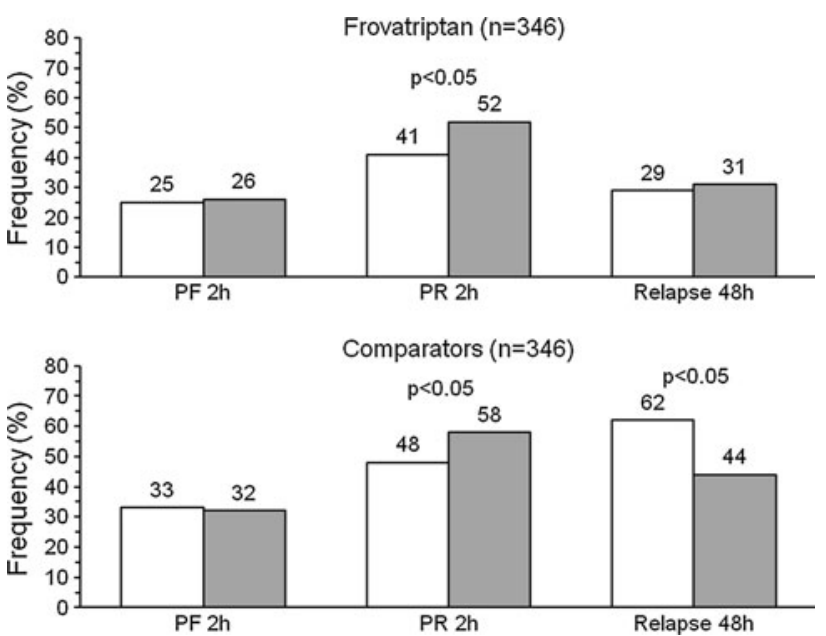

Fig. 1 Main study endpoints (pain free at $2 \mathrm{~h}$, pain relief at $2 \mathrm{~h}$ and relapses at $48 \mathrm{~h}$ ) in the 60 subjects with arterial hypertension (open bars) and in the 286 normotensive subjects (grey bars). Data are reported as relative (\%) frequencies as separately shown for patients treated with frovatriptan and the comparators 
subjects ( $p=\mathrm{NS}$ ). A similarly low proportion of subjects in the hypertensive and normotensive group $(1 \%)$ was withdrawn from the study due an adverse drug reaction.

\section{Discussion}

In the present pooled analysis of three double-blind, randomized, cross-over, national studies, acute treatment of migraine attacks with frovatriptan and other triptans (including rizatriptan, zolmitriptan and almotriptan), resulted in no differences in the proportions of pain-free episodes at $2 \mathrm{~h}$ between hypertensive and normotensive subjects. Conversely, pain relief was more difficult to achieve at $2 \mathrm{~h}$ in the subjects with high blood pressure, with any triptan. Finally, the relapse occurred more often in hypertensive than in normotensive subjects when attacks were treated with the comparators, but not with frovatriptan.

Albeit, we admittedly acknowledge the post hoc nature of our analysis, nevertheless our report stands as the first large comparative systematic analysis of head-to-head trials of frovatriptan vs. other triptans in hypertensive subjects. The study results show that treating an acute migraine attack with a drug of the triptan class is more difficult in presence of high blood pressure, with some differences among triptans. In particular, frovatriptan seems to be associated with a similarly good sustained relieving effect on migraine symptoms, in both hypertensive and normotensive subjects. This is not the case for the other triptans, showing a lower persistence in potency in case of concomitant hypertension. Such a finding is not surprising, because frovatriptan is known to have a long half life, this possibly determining a low rate of headache recurrence $[11,14,15]$.

Triptans are active mainly at the cranial vasculature than in other vascular beds, but they can cause some peripheral vasoconstriction and thus a potentially harmful and rise in blood pressure in case of uncontrolled hypertension [16]. In our study, which deliberately excluded patients with uncontrolled blood pressure, triptan therapy was not associated with any increase in blood pressure in the hypertensive subjects. Rather, we observed a blood pressure reduction, which can be possibly explained by a white-coat effect occurring during the first visits, because no changes in antihypertensive therapy occurred during the follow-up [17]. In addition, we observed neither any increase in heart rate nor a larger prevalence of adverse drug reactions in hypertensive subjects, a finding which is consistent with that of previous reports on the good cardiovascular tolerability of triptans [18-20].

In conclusion, our systematic analysis of individual data of double-blind, randomized, cross-over trials, suggests that hypertensive individuals in general tend to be less responsive than normotensive migraineurs to triptan therapy. However, frovatriptan seems to offer the advantage of a lower risk of recurrence and thus a more sustained effect than the other triptans in both hypertensive and normotensive subjects.

Acknowledgments The present study was supported by Istituto Lusofarmaco d'Italia S.p.A.

Conflict of interest All authors have occasionally served as scientific consultants for manufacturers of frovatriptan, rizatriptan, zolmitriptan or almotriptan. Deborha Pezzola and Dario Zava are employees of Istituto Lusofarmaco d'Italia.

\section{References}

1. Barbanti P, Aurilia C, Egeo G, Fofi L (2010) Hypertension as a risk factor for migraine chronification. Neurol Sci 31(1):S41-S43

2. Mancia G, Rosei EA, Ambrosioni E, Avino F, Carolei A, Daccò M, Di Giacomo G, Ferri C, Grazioli I, Melzi G, Nappi G, Pinessi L, Trimarco B, Zanchin G, MIRACLES Study Group (2011) Hypertension and migraine comorbidity: prevalence and risk of cerebrovascular events: evidence from a large, multicenter, cross-sectional survey in Italy (MIRACLES study). J Hypertens 29:309-318

3. Pietrini U, De Luca M, De Santis G (2005) Hypertension in headache patients? A clinical study. Acta Neurol Scand 112: 259-264

4. Williams FM, Cherkas LF, Spector TD, MacGregor AJ (2004) A common genetic factor underlies hypertension and other cardiovascular disorders. BMC Cardiovasc Disord 4:20

5. Bigal ME, Kurth T, Hu H, Santanello N, Lipton RB (2009) Migraine and cardiovascular disease: possible mechanisms of interaction. Neurology 72:1864-1871

6. Mathew NT (1999) Migraine and hypertension. Cephalalgia 19(25):17-19

7. Loder E (2010) Triptan therapy in migraine. N Engl J Med 363:63-70

8. Savi L, Omboni S, Lisotto C, Zanchin G, Ferrari MD, Zava D, Pinessi L (2011) A double-blind, randomized, multicenter, Italian study of frovatriptan versus rizatriptan for the acute treatment of migraine. J Headache Pain 12:219-226

9. Tullo V, Allais G, Ferrari MD, Curone M, Mea E, Omboni S, Benedetto C, Zava D, Bussone G (2010) Frovatriptan versus zolmitriptan for the acute treatment of migraine: a double-blind, randomized, multicenter, Italian study. Neurol Sci 31(1):S51-S54

10. Bartolini M, Giamberardino MA, Lisotto C, Martelletti P, Moscato D, Panascia B, Savi L, Pini LA, Sances G, Santoro P, Zanchin G, Omboni S, Ferrari MD, Brighina F, Fierro B (2011) A double-blind, randomized, multicenter, Italian study of frovatriptan versus almotriptan for the acute treatment of migraine. J Headache Pain 12:361-368

11. Sanford M (2012) Frovatriptan: a review of its use in the acute treatment of migraine. CNS Drugs 26:791-811

12. Headache Classification Subcommittee of the International Headache Society (2004) The international classification of headache disorders: 2nd edition. Cephalalgia 24(1):9-160

13. Parati G, Omboni S, Palatini P, Rizzoni D, Bilo G, Valentini M, Rosei EA, Mancia G (2008) Italian society of hypertension guidelines for conventional and automated blood pressure measurement in the office, at home and over 24 hours. High Blood Press Cardiovasc Prev 15:283-310

14. Géraud G, Keywood C, Senard JM (2003) Migraine headache recurrence: relationship to clinical, pharmacological, and pharmacokinetic properties of triptans. Headache 43:376-388 
15. Negro A, Lionetto L, Casolla B, Lala N, Simmaco M, Martelletti $P$ (2011) Pharmacokinetic evaluation of frovatriptan. Expert Opin Drug Metab Toxicol 7:1449-1458

16. Johnston MM, Rapoport AM (2010) Triptans for the management of migraine. Drugs 70:1505-1518

17. Parati G, Mancia G (2003) White coat effect: semantics, assessment and pathophysiological implications. J Hypertens 21: $481-486$
18. Jamieson DG (2002) The safety of triptans in the treatment of patients with migraine. Am J Med 112:135-140

19. Elkind AH, Satin LZ, Nila A, Keywood C (2004) Frovatriptan use in migraineurs with or at high risk of coronary artery disease. Headache 44:403-410

20. Velentgas P, Cole JA, Mo J, Sikes CR, Walker AM (2004) Severe vascular events in migraine patients. Headache 44:642-651 